\title{
Early administration of erythropoietin in extremely very low birth weight preterms
}

\author{
Mihaela Demetrian' ${ }^{1}$ Andreea Avramescu', Roxana lliescu' ${ }^{1}$, Andra Pirnuta', \\ Alecsandra Ana Irimie ${ }^{2}$, Vlad Dima ${ }^{1}$ \\ ${ }^{1}$ Filantropia Clinical Hospital of Obstetric, Bucharest, Romania \\ ${ }^{2}$ School of Sociology and Social Work, University of Bucharest, Romania
}

\begin{abstract}
Objectives. The present study is tryng to ascertain if EPO can be administred "early" (before 8 days of life) top revent or reduce the need for blood transfusions. As secondary objectives we aim to observe eficiency and safety when using early EPO with regards to reducing specific ELBW comorbidities.

Methodology. Prospective, randomised clinical study, that included 109 preterm babies with GA 30 wk, and BW $1,250 \mathrm{~g}$, born in our unit between January 2018 and June 2019. The treatment we used was early EPO within the first seven days of life, concomitent an oral iron supplement. According erythropoietin therapy, preterms were randomised in EPO group ( $n-40)$ and control group $(n-69)$.

Results. During hospitalization, there were 51 blood transfusions in the two groups: 13 in the EPO group and 38 in the control group. As for blood transfusions mean, it was $1.1 \pm 0.7$ for the EPO group (1-3) versus $1.5 \pm 1.2$ (1-6) for the control group, p 0.25 . There were statistically significant differences between the blood transfusions mean volume in the two groups $35.4 \pm 19.3 \mathrm{ml}$ for the EPO group versus $53.5 \pm 23.8 \mathrm{ml}$ for the control group, $\mathrm{p} 0.045$. There were no significant differences in IVH incidence ( $>$ gr. 3) between the two groups. Fisher's exact test showed that there was no influence of EPO on brain hemorrhage $\left(X^{2}=0.86, p=0.38\right)$, intestinal tract $\left(X^{2}=2.89, p=1.23\right)$, lung tissue $\left(X^{2}=\right.$ $0.7, p=1)$, or the incidence of retinopathy of prematurity $\left(X^{2}=0.42, p=0.59\right)$.

Conclusions. In our study, the early initiation of erythropoietin (EPO) at less than eight days, reduced the need for transfusions by 0.5 transfusions/patient. The total volume (ml/kg/patient) of transfused blood was reduced by $18 \mathrm{ml}$. Although the results from the recent meta-analyzes showed a moderate quality of evidence that EPO reduces intraventricular hemorrhage (IVH), periventricular leukomalacia (PVL) and NEC, the results of our study did not prove this.
\end{abstract}

Keywords: anemia of prematurity, early erythropoietin, transfusions

\section{INTRODUCTION AND STUDY PURPOSES}

PRBC transfusions continue to be an ongoing debate subject amongst neonatologists. Controversies arise mostly about the timing or opportunity of transfusion, aplying a liberal or more restrictive guidelines and short or long time effects. However, $80 \%$ of

VLBW preterms will receive at least one blood transfusion by the end of hospital stay because of frequent blood sampling or anemia of prematurity. Most transfusions happen in the first three to four weeks of life. Old and stable preterms respond better to EPO and will receive few transfusions. ELBW preterms, that are sick and need blood transfusions shortly after birth, respond inconsistently to EPO. This suggests that EPO is a stronger erythropoietic stimulant in more mature preterms. ELBW preterms are more susceptible to transfusions even with EPO stimulated erythropoiesis (1). Furthermore, ELBW preterms have a smaller blood volume, and repeated blood sampling often require "early" transfusions, as opposed to "late" transfusions that are more characteristic to anemia of prematurity (2). Low serum erythropoietin levels in premature babies offer a good motivation for the use of EPO to prevent or treat anemia. For a better documentation, we accessed the Cochrane Database of Systematic Reviews, the keywords being early EPO administration in VLBW babies. Several study meta-analyses exist, the last one dating from 2017 (3). This meta-analysis also studied the non-hematological effects of erythropoietin therapy and concluded that early EPO administration reduces the number of transfusions, the volume of blood needed and multiple donor exposure. However, the differences between the EPO and the control group were minimal and with limited clinical importance. Mortality 
and morbidity rates, including IVH and NEC, were not significantly modified by early EPO therapy.

\section{OBJECTIVES}

The present study is trying to ascertain if EPO can be administred "early" (before 8 days of life) to prevent or reduce the need for blood transfusions. Unlike late EPO treatment, there are better odds that the premature babies wouldn't have received any transfusion before entering the study. As secondary objectives we aim to observe eficiency and safety when using early EPO with regards to reducing neurological injuries and feeding intolerance/NEC; also we aim to observe if early use can influence specific ELBW comorbidities (retinopathy of prematurity ROP, bronchopulmonary displasia BPD).

\section{METHODOLOGY}

The present study included 109 preterm babies with $\mathrm{GA} \leq 30 \mathrm{wk}$, and $\mathrm{BW} \leq 1,250 \mathrm{~g}$, born between January 2018 and June 2019 (18 months) in our unit. Depending on EPO administration, the patients were randomised in two groups: the EPO group and the control group. Inclusion criteria: $\mathrm{GA} \leq 30 \mathrm{wk}$ and BW $\leq 1,250 \mathrm{~g}$. Exclusion criteria: congenital malformation/genetic syndromes, TORCH, severe birth asphyxia, IVH $>$ grade 3, Rhesus hemolytic disease. For all preterms we employed strategies to minimise blood loss and reduce multiple donor exposure: delayed cord clamping, minimising blood sampling, and good adherence to transfusion guidelines. The treatment we used was "early" EPO within the first seven days of life. (4). Treatment plan: Binocrit (Epoetin alfa) prefiled syringes, $1000 \mathrm{IU} / \mathrm{ml}$; dosage $400 \mathrm{IU} /$ $\mathrm{kg} /$ dose, (3 times a wk), subcutaneous. The length of therapy was 6 weeks, every patients receiving aproximately 18 doses of EPO.

Oral iron supplements were initiated when enteral nutrition reached $75 \%$ of daily needs, or $60 \mathrm{ml} / \mathrm{kg} /$ day. The preffered dosage: was $6 \mathrm{mg} / \mathrm{kg} /$ day, which could be increased up to $8-10 \mathrm{mg} / \mathrm{kg} /$ day when plasmatic iron levels dropped below $60 \mathrm{mg} / \mathrm{dl}$.

We monitored weekly $\mathrm{CBC}$ and serum iron levels. We kept records of: blood amounts needed for laboratory tests, number of PRBC transfusions, the volume of blood transfused, the postnatal age (days) and the target value of hemoglobin and hematocrit for the first transfusion. Also, we looked for potential nonerythropoietic effects of EPO therapy. The gut trophic and protector effect was evaluated by: onset of enteral nutrition, the amount of proteins/calories at 14 days, clinical aspects of NEC (Bell clasification grade $>2$ ). The neuroprotection effect was evaluated by: cerebral lesions like IVH and PVL $(4,5)$. All patients were included in the scree- ning for retinopathy of prematurity (ROP) $(6,7)$. The study was approved by the unit's Board of Ethics and parents gave consent for EPO and/or blood transfusion. All the data were collected with Epi Info 7 and were processed in the Analysis segment.

\section{RESULTS}

We included 116 preterms and collected data for 109 of them: 40 have received EPO therapy in the first week of life, and 69 of them received only oral iron supplements. Gestational age varied between 23-30 wk $(27.4 \pm 1.8$ EPO group vs $28.6 \pm 1.9-$ control group $)$, and BW between 550 and 1,300 grams (mean $969 \pm 186$ EPO group vs. 1,096 \pm 275 grams control group).

The compared data between two groups are shown in table 1. The EPO group all needed mechanical ventilation and developed more severe forms of RDS. 33 preterms from the EPO group (75\%) needed surfactant therapy and from the control group only 30 $(42 \%), p=0.001$. Minimally invasive surfactant administration (LISA/INSURE) was predominant in the control group ( $65 \%$ vs $18 \%$ ). In the EPO group invasive ventilation and increased MV period were more frequent: mean 13.1 vs 9.5 days, $p=0.21$. The EPO group had more severe forms of RDS, more frequent hemodynamic instability, and required increased inotropic support: $67.5 \%$ vs $27.5 \%, p=0.0034$. Although oxygen therapy length in the EPO group was higher (mean 36.3 vs 26.9 days), the incidence of BPD wasn't significantly different between the two groups: $12.5 \%$ (EPO) vs $14.3 \%$ (control), $\mathrm{p}=0.77$. There were no notable differences nutritional-wise: enteral nutrition onset happened generally in the first two days of life (1.6 vs 1.8 days) with a mean parenteral nutrition lengh of ten days, caloric intake was similar (135 cal $/ \mathrm{kg})$, but with a higher weight gain in the control group (114 vs. 93 grams) at 14 days of life, $p=0.05$.

\section{Hemoglobin and hematocrit curves}

We observed a more abrupt fall in hemoglobin and hematocrit in the control group beginning with week 4 of life ( $\sim 28$ days) up to week 7, the values being equal at discharge. The same evolution was observed hematocrit - wise (6). A split-plot ANOVA showed that the difference between $\mathrm{Hb} 1$ and $\mathrm{Hb} 10$ dropped significantly in the control group vs the EPO group $(\mathrm{F}=6.92, \mathrm{p}=0.01)$. Another test split plot ANOVA showed that the difference between Hct 10 (at discharge) and Hct 1 (at birth) drop was significantly higher in the control group vs the EPO group $(\mathrm{F}=9.64$, $\mathrm{p}=0.00$ ) (see Fig. 1, Fig. 2, Fig. 3, Fig. 4). The mean corpuscular volumes curves followed the same pattern: high volume at birth (115-117 pg) that decreased 
with postnatal age. There where no differences between the evolution of MCV in the two groups, corresponding with literature available data (8).
Blood transfusions. During hospitalization, there were 51 blood transfusions in the two groups: 13 in the EPO group and 38 in the control group. The post-

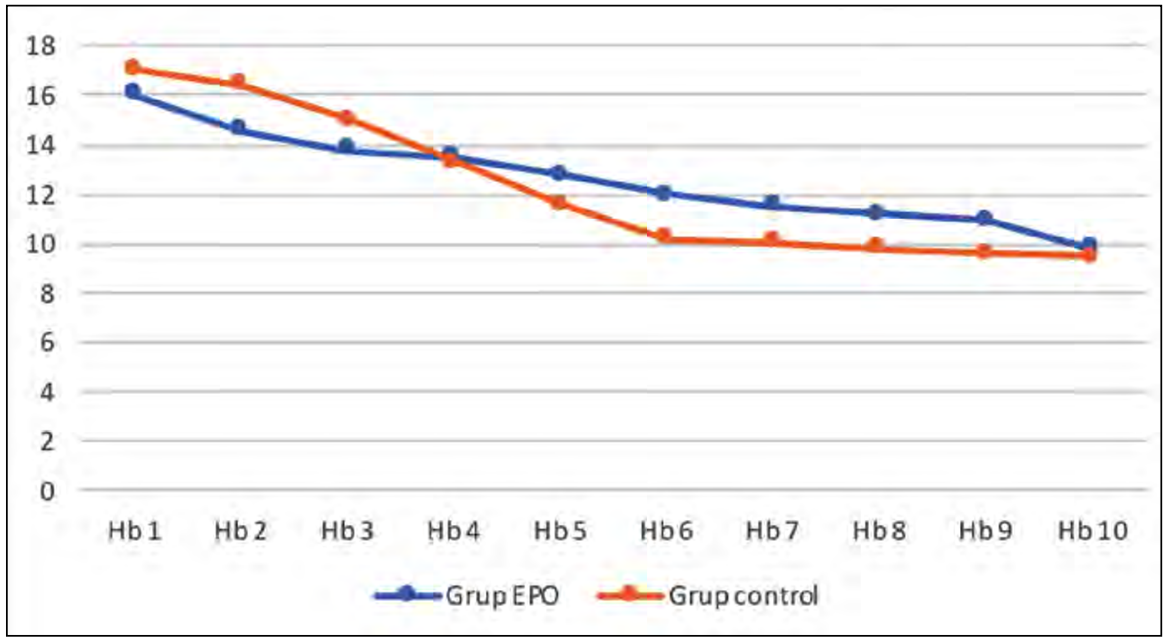

FIGURE 1. Hemoglobin curves in two groups

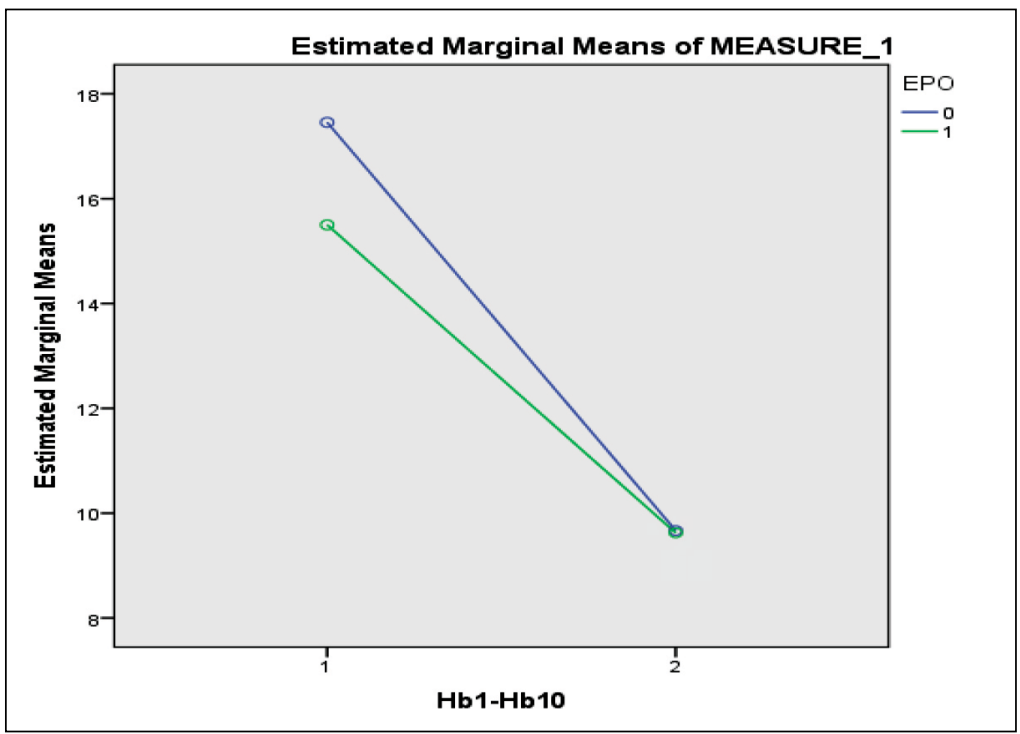

FIGURE 2. Split-plot Anova - Hemoglobin variations in two groups

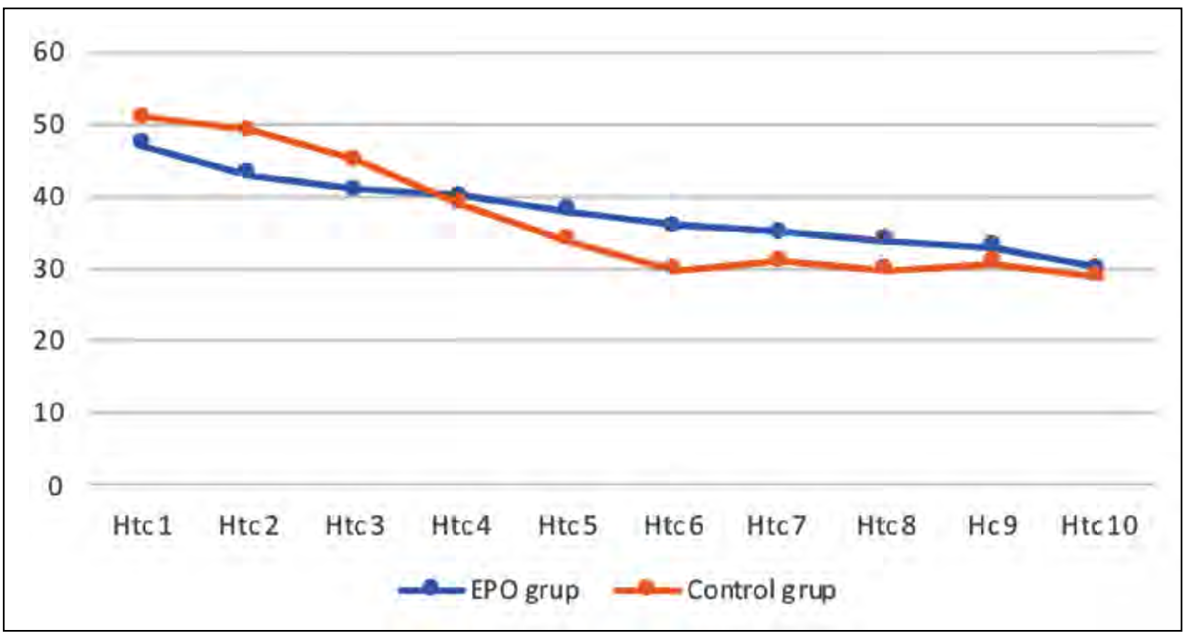

FIGURE 3. Hematocrit curves in two groups 


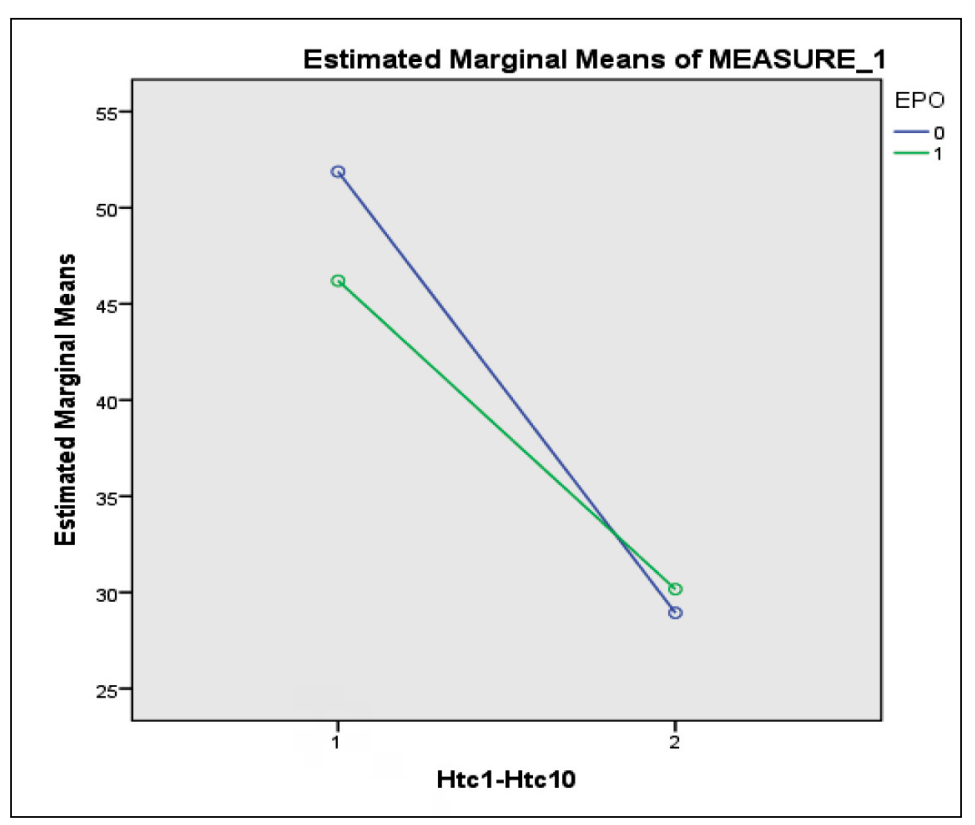

FIGURE 4. Split-plot Anova - Hematocrit variations in two groups natal age when the first transfusion was given was approx 35 days with a variation of 1-88 days, and was not significantly different in the two groups $(29,3 \pm 23,5$ EPO versus 37,1 $\pm 19,7$ days control group) p 0.25 .

Because the same transfusion guideline was applied, there where no significant differences hematocrit and hemoglobin - wise: $8,2 \pm 2$ versus $7,7 \pm 1,5 \mathrm{~g} / \mathrm{dl}$, p 0.18 and 27,3 versus $23,5 \pm 4,8 \%$, p 0.73 .

\section{Red blood cell transfusions}

During the hospitalization, there were 51 transfusions in the two groups: 13 in the EPO group and 38

TABLE 1. Demographic and clinical characteristics of the two groups

\begin{tabular}{|l|c|c|c|}
\hline Variables & EPO group (n-40) & Control group (n-69) & P value \\
\hline Gestational age (wk) & $27 \pm 1.8(23-30)$ & $28 \pm 1.9(24-30)$ & 0.08 \\
\hline Birth weight (g) & $969 \pm 43(650-1,300)$ & $1,096 \pm 27(550-1,250)$ & 0.05 \\
\hline Corticosteroids prophylaxis & $65 \%(26)$ & $59 \%(41)$ & 0.58 \\
\hline C-section (\%; $n)$ & $76 \%(30 / 40)$ & $60 \%(40 / 71)$ & 0.08 \\
\hline Preeclampsia (\%; $n)$ & $13 \%(5)$ & $39 \%(13)$ & 0.11 \\
\hline Chorioamnionitis & $12 \%(4)$ & $10 \%(7)$ & 0.4 \\
\hline Apgar score at 5 min & $6.6 \pm 1.3$ & $6.4 \pm 1$ & 0.44 \\
\hline Mechanical ventilation & $84.3 \%(59)$ & $100 \%(40)$ & 0.07 \\
\hline Non-invasive ventilation (SNIPPV*) & $25 \%(10)$ & 0.01 \\
\hline Surfactant & $55.9 \%(33)$ & $30(42 \%)$ & 0.001 \\
\hline LISA/INSURE* & $30(75 \%)$ & $65 \%(19)$ & 0.01 \\
\hline Mechanical ventilation length (days) & $18 \%(5)$ & $9.5 \pm 1.7(2-70)$ & 0.21 \\
\hline Oxygen therapy length (days) & $13.1 \pm 1.3(2-39)$ & $26.9 \pm 4.3(1-117)$ & 0.06 \\
\hline Inotropes & $36.3 \pm 4.8(1-94)$ & $27.5 \%(19)$ & 0.0034 \\
\hline Persistent ductus arteriosus treated with Pedea & $67.5 \%(27)$ & $20 \%(14)$ & 0,65 \\
\hline Bronchopulmonary dysplasia & $15 \%(6)$ & $12.5 \%(5)$ & 0.77 \\
\hline Enteral nutrition onset (days) & $14.3 \%(10)$ & $1.8 \pm 1.7$ & 0.54 \\
\hline Parenteral nutrition length (days) & $1.6 \pm 1$ & $9.1 \pm 5.2$ & 0.09 \\
\hline Calorie/kg at 14 days of life & $10.7 \pm 5.6$ & $134 \pm 21$ & 0.70 \\
\hline Protein intake at 14 days of life ()g/kg/day & $136.3 \pm 26$ & $3.3 \pm 0.5$ & 0.86 \\
\hline Weight increase at 14 days of life (grams) & $3.3 \pm 0.4$ & $114 \pm 88$ & 0.05 \\
\hline Early onset sepsis & $93 \pm 34$ & $55 \%(37)$ & 0.02 \\
\hline Late onset sepsis & $28 \%(11)$ & $10.4 \%(7)$ & 0.75 \\
\hline Hospitalization length & $18 \%(7)$ & $63.9 \pm 24$ & 0.40 \\
\hline
\end{tabular}

*SNIPPV - synchronous nasal intermittent positive pressure ventilation, **LISA - low invasive surfactant administration,

INSURE - intubation-surfactant-extubation 
in the control group. The postnatal age at which the first transfusion was administered was approximately 35 days, with a variation of 1-88 days, and did not differ significantly between the two groups $(29.3 \pm$ 23.5 EPO versus $37.1 \pm 19.7$ days control group), $\mathrm{p}=0.25$.

Because the same transfusion protocol was applied, hemoglobin and hematocrit values did not have significant differences between the two groups: $8.2 \pm 2$ versus $7.7 \pm 1.5 \mathrm{~g} / \mathrm{dl}, \mathrm{p}=0.18$ and 27.3 versus $23.5 \pm$ $4.8 \%, \mathrm{p}=0.73$.

As for blood transfusions mean, it was $1.1 \pm 0.7$ for the EPO group (1-13) versus $1.5 \pm 1.2$ (1-6) for the control group, $p=0.25$. A Man-Whitney $U$ test showed that there was no statistically significant difference between the blood transfusions mean number in the EPO group $(\mathrm{Md}=1, \mathrm{n}=13)$ and the one in the control group $(\mathrm{Md}=1.5, \mathrm{n}=38)$. There were statistically significant differences between the blood transfusions mean volume in the two groups $35.4 \pm 19.3 \mathrm{ml}$ for the EPO group versus $53.5 \pm 23.8 \mathrm{ml}$ for the control group, p 0.045. By applying a Mann-Whitney U test we demonstrated a statistically significant difference between blood transfusions mean volume in the EPO group $(\mathrm{Md}=33, \mathrm{n}=13)$ and the control group $(\mathrm{Md}=46.5$, $\mathrm{n}=38$ ). Because factors that associate with the need for transfusion can overlap with those that contribute to the specific comorbidities of ELBW preterms, we used linear regression analysis to define the influence of certain risk factors like gestational age, the need for inotropic support, mechanical ventilation length, early/late onset sepsis, amount of blood sampling. We discovered a negative correlation between GA (p 0.019), mechanical ventilation length $(p=0.03)$ and the need for transfusion. It is worth noting that although the premature babies in the EPO group had more severe forms of respiratory distress and needed more mechanical ventilation, the number and volume of blood transfusions was lower, also because blood gas sampling was minimal and carefully assessed. The latter reflects also in the mean blood sampling volume/patient, which wasn't significantly different between the two groups $(22.4 \pm 7.5$ EPO group vs $19.2 \pm 5.7$, control group, $p=0.1$ ). Most transfusions were administered after 28 days of life in both groups.

\section{The non-erythropoietic effects of EPO}

One of the proposed scopes of the study was to observe the effect of erythropoietin on intraventricular bleeds, considering its neuroprotection effect. There where no significant differences of IVH (> grade 3) and PVL incidence in the two groups. An exact Fisher test showed that there was no influence of EPO in the onset of brain hemorrhages $\left(\mathrm{X}^{2}=0.86, \mathrm{p}=0.38\right)$.
Also, we could not demonstrate the protector effect of EPO on the gut mucosa: 2 patients from the EPO group (5\%) and 11 from the control group (16\%) presented NEC, stages 1 and 2. The exact Fisher test showed that there was no EPO influence over the gut mucosa $\left(\mathrm{X}^{2}=2.89, \mathrm{p}=1.23\right)$, the pulmonary tissue $\left(\mathrm{X}^{2}=0.7, \mathrm{p}=1\right)$, or ROP incidence $\left(\mathrm{X}^{2}=0.42\right.$, $\mathrm{p}=0.59)-$ table no 2 .

Severe ROP ( $>$ grade 3 ) and NEC incidence in our study could not be correlated with blood transfusions number ( $\mathrm{p} 0.88)$, volume $(\mathrm{p}=0.71)$ and postnatal age $(p=0.88)$ when blood transfusions where given (9).

TABLE 2. The incidence of specific comorbidities in the two groups

\begin{tabular}{|l|c|c|c|c|}
\hline Variables & $\begin{array}{c}\text { EPO } \\
\text { group }\end{array}$ & $\begin{array}{c}\text { Control } \\
\text { group }\end{array}$ & $\begin{array}{c}\text { Exact } \\
\text { Fisher } \\
\text { test }\end{array}$ & $\begin{array}{c}\text { P } \\
\text { value }\end{array}$ \\
\hline $\begin{array}{l}\text { Incidence of cerebral } \\
\text { lessions } \\
\text { (IVH > gr. 3, PVL) }\end{array}$ & $3.5 \%(3)$ & $5.5 \%(6)$ & $\mathrm{X}^{2}=0.86$ & 0.38 \\
\hline $\begin{array}{l}\text { Incidence of } \\
\text { ROP> gr. 3 }\end{array}$ & $5.2 \%(2)$ & $1.64 \%(1)$ & $\mathrm{X}^{2}=0.42$ & 0.59 \\
\hline $\begin{array}{l}\text { Incidence of NEC } \\
\text { std. 1-2 }\end{array}$ & $5.1 \%(2)$ & $15.9 \%(11)$ & $\mathrm{X}^{2}=2.89$ & 1.23 \\
\hline Incidence of BPD & $12.5 \%(5)$ & $14.3 \%(10)$ & $\mathrm{X}^{2}=0.7$ & 1 \\
\hline
\end{tabular}

\section{DISCUSSIONS}

In our study, early EPO use in the first 8 days of life, reduced the need for transfusion by $0.5 /$ patient. The total blood transfusion volume $(\mathrm{ml} / \mathrm{kg} /$ patient) was reduced, as well as donor numbers amongst the randomized patients - but not for the transfused preterms. This facts are consistent with the study metaanalysis regarding ,early” EPO administration (3) which concluded that EPO significantly reduces the number of transfusions by one or more/patient, the volume of transfused blood and the number of multiple donor exposures. For all these results, the effect size was small and susceptible to limited clinical importance. Although the two groups were equal from a demographic point of view, the repiratory pathology in the EPO group was more severe, and so it was expected that the transfusional needs would be higher in these cases (10). It is possible that this difference in respiratory pathology between the two groups has influenced the EPO therapy results. In general, for these preterms, PRBC transfusions provide a certain hemoglobin level that depends on the level of cardiac and respiratory support required. For ELBW preterms, almost half of PRBC tranfusions are administered in the first two weeks of life, when cardiac and respiratory pathologies are more severe and blood sampling more frequent; in the first week of life, losses through blood 
sampling can reach 10-30\% of total blood volume (10$25 \mathrm{ml} / \mathrm{kg}$ ) (11). In our study we could not prove the effect of erythropoietin in neuroprotection; the number of patients with cerebral lesions (IVH $>$ gr. 3 ) was very low in the two groups and it is hard to significantly correlate statistically. In the latest meta-analysis review on EPO studies, the incidence of IVH (grade 3 and 4) and PVL dropped significantly. Regarding ROP, we did not observe any aggresive forms, athough there have been studies which demonstrated a significant increase of ROP (>grade 3 ) rate, when administering early EPO (6). At the same time, PRBC transfusion in the first 10 days of life was associated with a 4-fold increase of severe retinopathy risk, regardless of gestational age or bronchopulmonary displasia (9-11). The protective effects of erythropoietin on the gut mucosa could not be proven in our study. There were only mild forms of NEC (stages 1 and 2) and it was difficult to achieve a correlation with the protective effect of EPO vs PRBC transfusions. Oxygen alteration or disruption of mezenteric perfusion were implicated in the phenomenon know as TRAG - transfusion related acute injury of gut (1216). Although the results related to the transfusion im-

\section{REFERENCES}

1. Kotto-Kome AC, Garcia MG, Calhoun DA, Christensen RD. Effect of beginning recombinant erythropoietin treatment within the first week of life, among very-low-birth-weight neonates, on "early" and "late" erythrocyte transfusions a meta-analysis. Journal of Perinatology 2004; 24(1): 24-9.

2. Garcia MG, Hutson AD, Christensen RD. Effect of recombinant erythropoietin on "late" transfusion in the neonatal intensive care unit: A meta-analysis. Journal of Perinatology 2002;22(2);108-11.

3. Ohlsson A, Aher SM. Early erythropoietin for preventing red blood cell transfusion in preterm and/or low birth weight infants. Cochrane Database of Systematic Reviews 2014, Up-Date 2017, Issue 4. Art. No.: CD004863.

4. Juul S. Neuroprotective role of erythropoietin in neonates. Journal of Maternal-Fetal \& Neonatal Medicine 2012; 25 (Suppl 4):105-7.

5. Jakab A., Ruegger C., Bucher HU, Makki M, Huppi PS,Hagmann C, Swis EPO Neuroprotection Trial Group Network based statistics reveals trophic and neuroprotective effect of early high dose erythropoetin on brain connectivity in very preterm infants. Neuroimag Clin 2019; 22: 101806 Epub 2019 Apr 1.

6. Ohlsson, Aher SM, Early erythropoietin for preventing red blood cell transfusion in preterm and/or low birth weight infants. Cochrane Database Syst Rev. 2012 Sep 12 ;(9): CD004863.

7. Fierson WM. American Academy of Pediatrics Section on O, American Academy of $\mathrm{O}$, American Association for Pediatric $\mathrm{O}$, Strabismus, American Association of Certified O. Screening examination of premature infants for retinopathy of prematurity. Pediatrics. 2013; 131:189-95.

8. Robert D. Christensen, MD, Erick Henry, MPH, Jeff Jopling, BS, and Susan E. Wiedmeier, MD The CBC: Reference Ranges for Neonates, Seminars in Perinatology, 2009 Elsevier.

9. Lust C, Vesouli Z, Jackups R, Liao S, Rao R, Malthur AM, Early red cell transfusion is associated with development of severe retinopathy of prematurity. J Perinatol. 2019, Mar, 39(3):393-400. pact of these meta-analyses cannot recommend, at the moment, the use of EPO in the standard treatment of prematurity anemia, its non-erythropoietic effects (especially neuroprotection) represent a promise and a challenge to continue further studies (17).

\section{CONCLUSIONS}

In our study, the early use of EPO in the first 8 days of life reduced the need for blood transfusions by $0.5 /$ patient. The total transfusion volume $(\mathrm{ml} / \mathrm{kg} / \mathrm{pati}$ ent) was reduced by $18 \mathrm{ml}$. Early EPO use can reduce the number of transfusions by one or more/patient, the volume of blood needed is smaller, as well as the number of donors/patient. Although statistically significant, these reductions have limited clinical importance. In our study, like in the current meta-analyses updates for early EPO use, with high quality evidence according to GRADE, there is no significant increase of ROP ( $\geq$ grade 3 ) rate. Although recent metaanalyses results showed (moderate quality evidence) that EPO reduces IVH, PVL and NEC incidence, our study did not demonstrate this aspect.

Conflict of interest: none declared Financial support: none declared

10. Howarth C, Banerjee I, Aladangady N, Red blood cell transfusions in preterm infants: current evidence and controversies. Neonatology 2018; 114:7-16.

11. Wang Y, Chan O, Chiang M, Yang P. Red Blood Cell Transfusion and Clinical Outcomes in Extremely Low Birth Weight Preterm Infants. Pediatr Neonatol. 2017; 58(3):216. Epub 2016 Jul 5.

12. Dani C, Poggi C, Gozzini E, Leonardi V, Sereni A, Abbate R, Gori AM: Red blood cell transfusions can induce proinflammatory cytokines in preterm infants. Transfusion 2017; 57: 1304-1310.

13. Song J, Sun H, Xu F, Kang W. Recombinant human erythropoietin improves neurological outcomes in very preterm infants. Ann Neurol. 2016 Jul;80(1):24-34.

14. J. Blau, JM Calo, D Dozor, M Sutton, G Alpan, EF La Gamma. Transfusion-related acute gut injury: Necrotizing enterocolitis in very low birth weight neonates after packed red blood cell transfusion. J Pediatr, 158 (2011), pp. 403-409.

15. MB Wallenstein, YH Arain, KL Birnie, J Andrews, JP Palma, WE Benitz et al. Red blood cell transfusion is not associated with necrotizing enterocolitis: A review of consecutive transfusions in a tertiary neonatal intensive care unit. J Pediatr, 165 (2014), pp. 678-682.

16. Patel RM, Knezevic A, Shenvi N, Hinkes M, Keene S, Roback JD, Easley KA, Josephson CD. Association of red blood cell transfusion, anemia, and necrotizing enterocolitis in very low-birth-weight infants. JAMA 2016; 315: 889-897.

17. Aher SM, Ohlsson A. Late erythropoiesis-stimulating agents to prevent red blood cell transfusion in preterm or low birth weight infants. Cochrane Database Syst Rev. 2019;2. 